\title{
Delayed but effective induction of mucosal memory immune responses against genital HSV-2 in the absence of secondary lymphoid organs
}

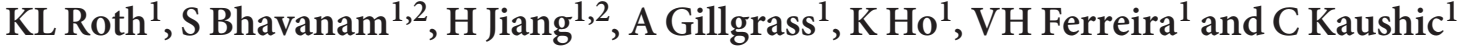

To examine whether local immunization in the absence of secondary lymphoid organs (SLOs) could establish effective antiviral memory responses in the female genital tract, we examined immunity in the vaginal tracts of $L T \alpha-/-$ mice, LT $\alpha-/-$ SPL (splenectomized), and control C57BL/6 (WT) mice. All three groups of mice were immunized intravaginally (IVAG) with attenuated thymidine kinase-negative (TK-) Herpes simplex virus type 2 (HSV-2) and challenged 4-6 weeks later with wild-type (WT) HSV-2. Both groups of $L T \alpha-/-$ mice exhibited delayed viral clearance and prolonged genital pathology after immunization. Following IVAG WT HSV-2 challenge, LT $\alpha-/-$ and LT $\alpha-/-$ SPL mice had significantly lower levels of HSV-2-specific IgG and IgA in the vaginal secretions. Although the frequency of $B$ and $T$ cells in the vaginal mucosa was comparable or higher in both groups of LT $\alpha-/-$ mice, lower frequency of HSV-2-specific interferon- $\gamma$ (IFN $\gamma$ )-producing CD3 + T cells was seen after immunization and after challenge, compared with WT group. Despite this, immunized mice in all three groups showed complete sterile protection against IVAG WT HSV-2 challenge. These results show that even in the absence of SLOs, IVAG immunization generates effector memory immune responses at genital mucosa that can provide antiviral protection against subsequent viral exposures. This will inform new strategies to design mucosal vaccines against sexually transmitted infections.

\section{INTRODUCTION}

The presence of a common immune system at mucosal sites, including intestinal, lung, and genitourinary tract, is well recognized. Some characteristics such as homing markers are shared among these sites; however, there are distinct differences between individual mucosal tissues. ${ }^{1,2}$ Studies have also shown that effective memory T-cell responses are generated in the lung mucosa during influenza infection in the absence of secondary lymphoid structures (SLOs). ${ }^{3}$ The site for the maintenance and generation of these memory responses was shown to be induced bronchial-associated lymphoid tissues. ${ }^{4}$ In a mouse model of genital herpes infection, we have also documented the development of induced vaginal-associated lymphoid tissue (iVALT) aggregates in the genital mucosa of immunized mice, which correlated with protection against Herpes simplex virus type 2 (HSV-2) infection following challenge. These iVALTs were found to contain primarily CD $4+\mathrm{T}$ cells, B cells, and CD11c + antigen-presenting cells. ${ }^{5}$ Furthermore, our studies suggested that the local microenvironment in genital tract plays a role in generating effective antiviral immune responses following immunization. ${ }^{5,6}$ We therefore decided to examine whether protective effector memory responses could be induced in the genital mucosa, against a viral infection, in the absence of SLOs. To do this, we utilized a lymphotoxin- $\alpha$ (LT $\alpha)$ knockout mouse model.

LT $\alpha$ is a member of the tumor necrosis factor family. The tumor necrosis factor family members, including LT $\alpha$, have been shown to be essential for the proper development of lymphoid tissues, including lymph nodes (LNs) and Peyer's patches, and for maintenance of the correct architecture of SLOs, including the spleen..$^{7-12}$ Knockout mice for both LT $\alpha$ and LT $\beta$ have been used in studies to demonstrate the importance of LT in lymphoid organogenesis. Whereas LT $\beta-/-$ mice maintain both the cervical and mesenteric LNs, ${ }^{10,13} \mathrm{LT} \alpha-/$ - mice lack all LNs, including mucosal ones. ${ }^{10} \mathrm{LT} \alpha-/$ - mice have also been shown to have significantly disorganized lymphoid

${ }^{1}$ McMaster Immunology Research Center, Michael G. DeGroote Center for Learning and Discovery, Department of Pathology and Molecular Medicine, McMaster University, Hamilton, Ontario, Canada. ${ }^{2}$ These authors contributed equally to this work.Correspondence: C Kaushic (kaushic@mcmaster.ca) 
structures within the spleen. Thus, LT $\alpha-/-$ mice, which lack SLOs, provide an effective tool for examining the role of SLOs in the generation and maintenance of adaptive immune responses to infectious agents. Antiviral immune responses in the absence of SLOs have been examined in both LT $\alpha-/$ - and LT $\beta-/-$ mice. ${ }^{14-18} \mathrm{LT} \alpha-/-$ mice have been shown to generate delayed but effective responses to influenza and MHV-68. ${ }^{16,17}$ However, during systemic infection with HSV, LT $\alpha-/-$ mice failed to develop effective CD8 + T-cell responses and clear the virus. ${ }^{15}$ Whether adequate antiviral memory immune responses can be mounted in the genital mucosa in response to mucosal immunization in the absence of SLOs is not known.

Genital tract mucosa is an important target for inducing immune responses against sexually transmitted pathogens. Genital herpes is one of the most common sexually transmitted infections. ${ }^{19}$ As of 2008 , it was estimated that 536 million people aged 15-49 years are infected globally, and 23.6 million people become newly infected every year. ${ }^{20}$ Despite the significant global health burden from HSV-2, attempts to develop herpes vaccines have failed since the $1930 \mathrm{~s}^{21,22}$ The most recent trial of a glycoprotein D (gD)-based HSV-2 vaccine showed a lack of efficacy, despite previous trials where partial protection was observed in women who were seronegative for both HSV-1 and HSV-2. ${ }^{23,24}$ The failure of conventional HSV-2 vaccines reiterate the importance of examining the local microenvironment in the female genital tract. ${ }^{25,26}$

In the present study we examined whether intravaginal (IVAG) immunization in the absence of SLOs could establish effective anti-HSV-2 memory responses in the female genital tract and hypothesized that the genital mucosa itself, without the help of any draining LNs, is capable of generating a protective antiviral immune response. LT $\alpha-/$ - mice were ovariectomized (OVX) to make mice susceptible to HSV-2 infection, and splenectomized (SPL) to remove all SLOs. Mice were then immunized IVAG with an attenuated strain of HSV-2, thymidine kinase-negative (TK ${ }^{-}$) HSV-2, and 4-6 weeks later challenged IVAG with wild-type HSV-2. LT $\alpha-/-$ mice, as well as wild-type (WT) controls, showed complete protection against genital HSV-2 challenge, although both groups of LT $\alpha-$ / - mice exhibited delayed viral clearance and prolonged genital pathology after immunization. Although local viral-specific antibody responses were compromised and T cell-mediated anti-HSV-2 responses were delayed in $\mathrm{LT} \alpha-/$ - mice, the immune responses generated were effective in protection against mucosal HSV-2 challenge in the genital mucosa.

\section{RESULTS}

\section{Protection against HSV-2 challenge in LT $\alpha-/-$ mice following IVAG immunization with TK- HSV-2}

Previously, we have shown that following IVAG immunization with TK ${ }^{-}$HSV-2, WT OVX female mice are completely protected against IVAG challenge. ${ }^{5}$ Removal of ovaries (OVX) makes mice susceptible to genital HSV-2 infection without hormonal manipulation. ${ }^{5,6}$ As LT $\alpha-/-$ mice completely lack draining LNs as well as Peyer's patches, we first examined whether IVAG immunization with $\mathrm{TK}^{-} \mathrm{HSV}-2$ would result in protection. To ensure the absence of all SLO, we removed the spleens in LT $\alpha-/$ - mice. Both LT $\alpha-/$ - OVX and LT $\alpha-/$ - OVX + SPL mice, along with WT OVX controls, were then immunized IVAG with $10^{5} \mathrm{PFU}$ of TK ${ }^{-} \mathrm{HSV}-2$, as previously described. ${ }^{5}$ At $4-6$ weeks after immunization, mice were challenged IVAG with $10^{5} \mathrm{PFU}$ of WT HSV-2. All three groups of mice showed $100 \%$ survival against HSV-2 infection after challenge (Figure 1). To show that all mice did in fact become infected, nonimmunized control groups were included. Following OVX and/or SPL, all three groups of mice were infected IVAG with $10^{5} \mathrm{PFU}$ of WT HSV-2. Mice in all three groups succumbed to infection within a week, as expected (Figure 1). Thus, IVAG immunization induced HSV2 -specific immune responses in all three groups of immunized mice, resulting in complete protection against high-dose genital HSV-2 challenge.

\section{Genital pathology in LT $\alpha-/-$ mice after immunization and after challenge}

To determine if the protection in all three groups of mice was comparable, gross pathology of the genital area was examined daily following $\mathrm{TK}^{-} \mathrm{HSV}-2$ immunization and WT HSV-2 challenge. In all, 7 of $9 \mathrm{WT}, 8$ of $10 \mathrm{LT} \alpha-/-$, and 10 of 10 LT $\alpha-$ / - SPL mice showed external pathology starting 6 to 7 days after immunization (Figure 2a). Although a majority of mice in the WT group showed mild pathology symptoms, higher pathology was noted in more mice in both groups of LT mice (Figure 2a and Table 1). Assessment of cumulative pathology scores for each group and average pathology per mouse, as described before, ${ }^{27}$ showed that mice in the WT group had the lowest average pathology score (29) compared with both $\mathrm{LT} \alpha-/$ - (40) and LT $\alpha-/$ - SPL (62) mice after immunization (Table 1). Following WT HSV-2 challenge 6 weeks after immunization, none of the mice in any of the three groups showed any pathology up to 21 days after challenge (Figure $2 \mathbf{b}$ ). In nonimmunized control groups, $\mathrm{LT} \alpha-/-$ and LT $\alpha-/-$ SPL mice developed pathology more rapidly than WT mice (Figure 2c).

\section{Viral titers in LT $\alpha-/-$ and LT $\alpha-/-$ SPL mice after immunization and after challenge}

Viral titers were measured in vaginal washes after immunization and after challenge to measure the control of viral replication and shedding in the genital tract by local immune responses. Previous studies have shown that viral shedding in vaginal washes occurs for 3-5 days after immunization in WT mice before virus is cleared. ${ }^{5,6,27}$ In the present study, similar results were seen in WT mice (Figure 3a). However, LT $\alpha-/-$ and LT $\alpha-/$ - SPL mice had prolonged viral shedding (Figure 3a). Overall, the viral titers were not significantly higher $(P>0.05)$ in the LT $\alpha-/$ - and LT $\alpha-/$ - SPL mice after immunization compared with WT mice. Mice in all three groups did not show any viral shedding after HSV-2 challenge (Figure $3 \mathbf{b}$ ). In nonimmunized controls, there was significant viral shedding in all three groups of mice on day 1 after infection that persisted over next 3-5 days, after which the vaginal pathology was too high to collect samples from the mice (Figure 3c). 

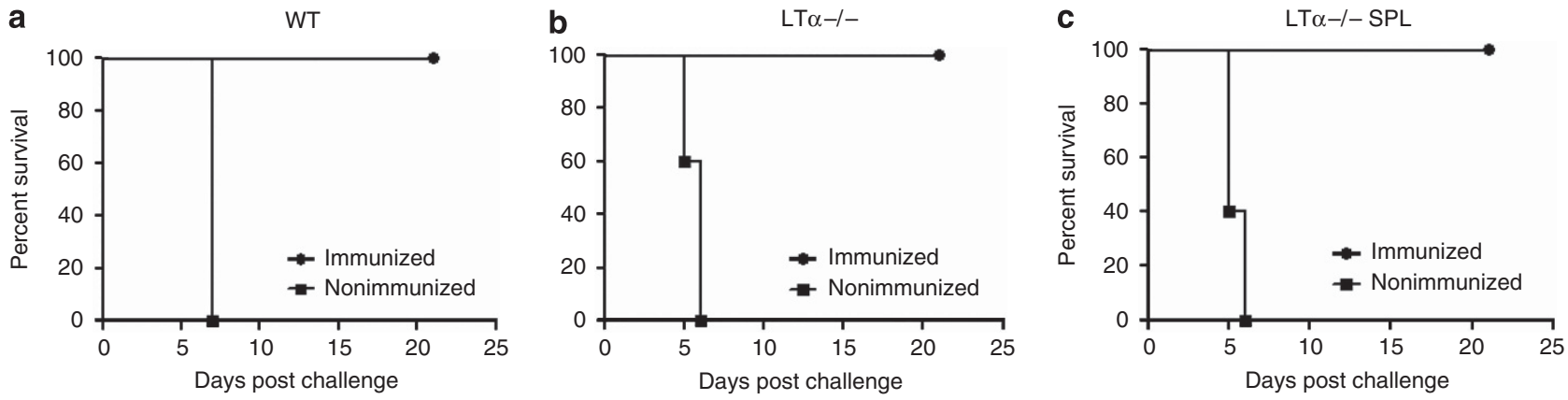

Figure 1 LT $\alpha-/-$ mice immunized IVAG with TK- HSV-2 are completely protected against genital HSV-2 challenge. (a) WT OVX, (b) LT $\alpha-/-$, and (c) $\mathrm{LT} \alpha-/-$ SPL mice were immunized IVAG with $10^{5} \mathrm{PFU}$ of TK- HSV-2, or left unimmunized as a control. At 4-6 weeks after immunization, mice were challenged IVAG with HSV-2, strain 333, and monitored daily for survival. Mice in all three immunized groups showed $100 \%$ survival. The results shown are pooled from three separate experiments. $n=21$ for WT OVX and LT $\alpha-/-$ OVX; $n=18$ for LT $\alpha-/-$ OVX+SPL. For nonimmunized (NI) controls, $n=5$ for all three groups of mice. HSV-2, Herpes simplex virus type 2; IVAG, intravaginal; LT $\alpha$, lymphotoxin- $\alpha$; OVX, ovariectomized; $\mathrm{SPL}$, splenectomized; $\mathrm{TK}^{-}$, thymidine kinase-negative; WT, wild type.
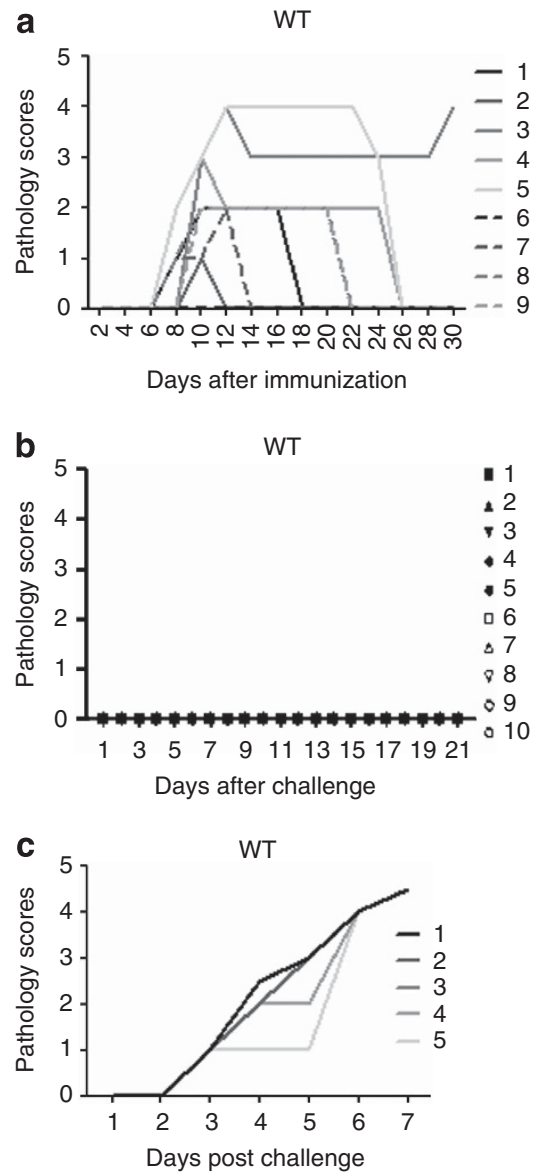

$\mathrm{LT} \alpha-/-$
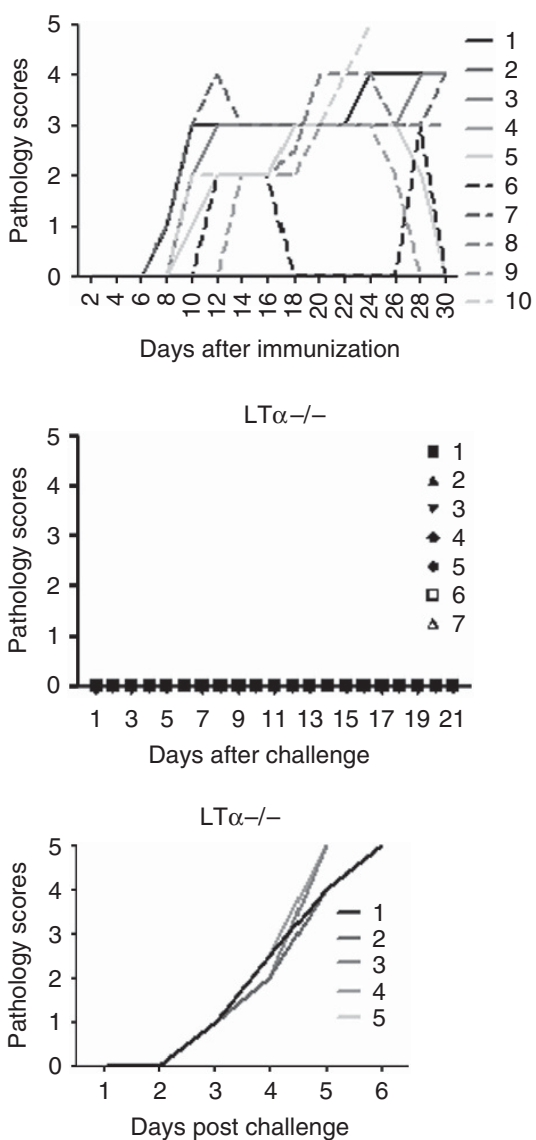
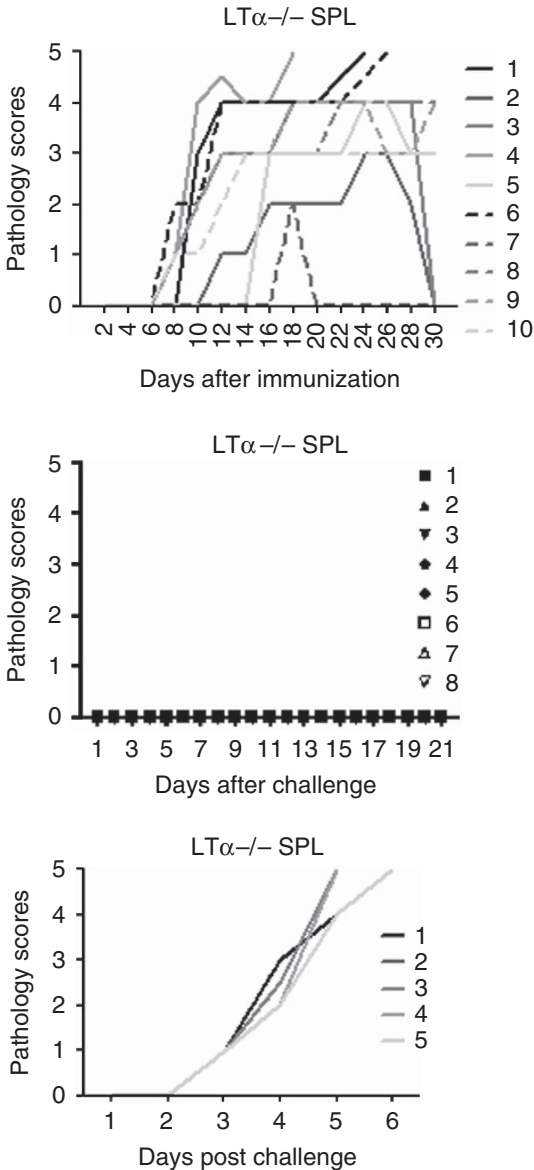

Figure $2 \mathrm{LT} \alpha-/$ - mice have higher pathology after immunization with TK- HSV-2 compared with WT mice, but no differences in pathology were seen after challenge. WT OVX, LT $\alpha-/-$ OVX, and LT $\alpha-/-$ OVX +SPL mice were immunized IVAG with $10^{5}$ PFU of TK- HSV-2, or left unimmunized as a control. At 4 to 6 weeks after immunization, mice were challenged IVAG with HSV-2, strain 333. Vaginal pathology was monitored daily (a) after immunization and (b) after challenge and (c) after infection in nonimmunized mice. The results shown are representative of four separate experiments with similar results. HSV-2, Herpes simplex virus type 2; IVAG, intravaginal; LT $\alpha$, lymphotoxin- $\alpha$; OVX, ovariectomized; SPL, splenectomized; TKthymidine kinase-negative; WT, wild type.

To confirm that there was no viral shedding after challenge, a more sensitive real-time PCR assay was performed to measure HSV-2 DNA (Supplementary Figure S1 online).
Viral shedding measured by real-time PCR confirmed the results seen by plaque-forming assay (Figure 3), with no viral shedding seen 7-12 days after immunization and no shedding 
Table 1 Pathology scores of WT OVX, LT $\alpha-/-$ OVX, and LT $\alpha-/-$ OVX + SPL mice following IVAG TK- HSV-2 immunization

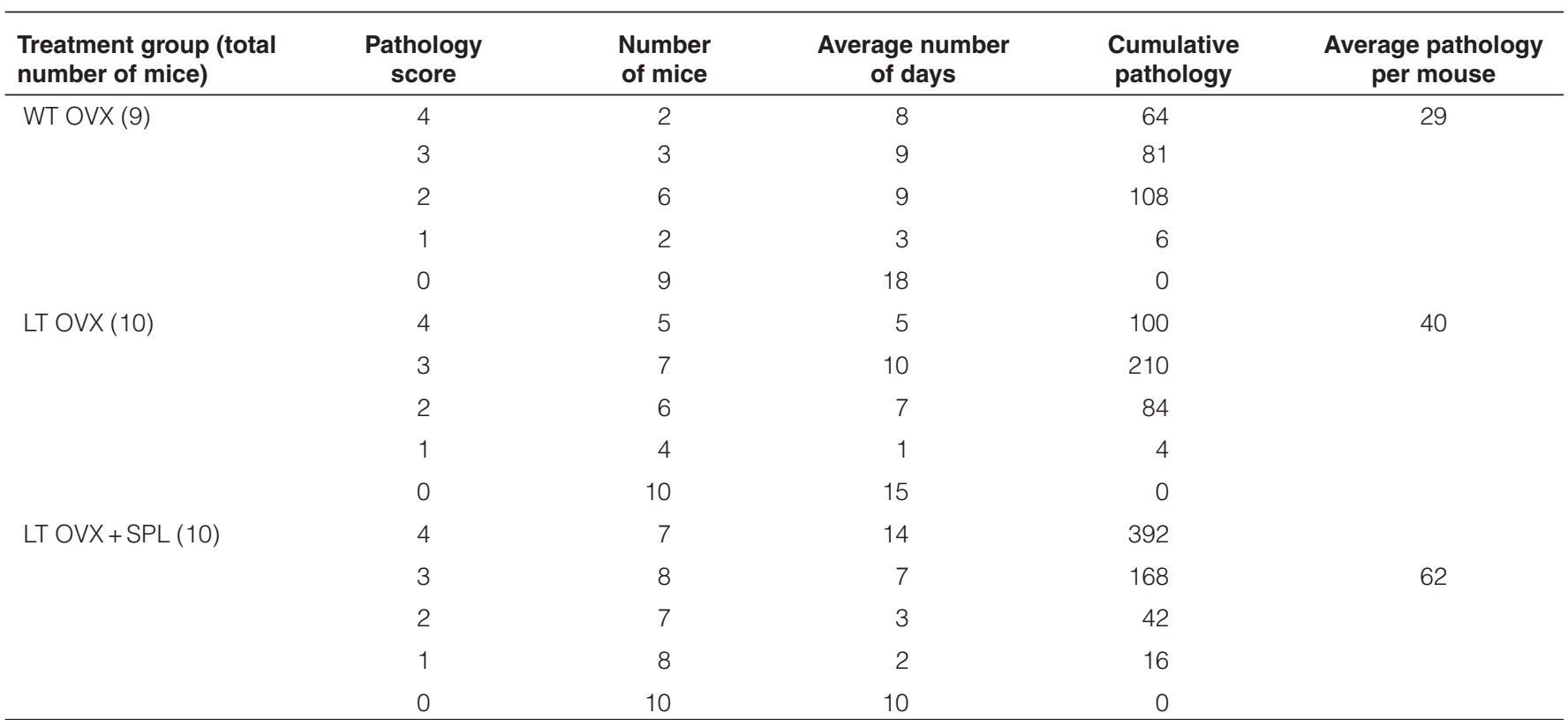

Abbreviations: HSV-2, Herpes simplex virus type 2; IVAG, intravaginal; LT $\alpha$, lymphotoxin- $\alpha$; OVX, ovariectomized; SPL, splenectomized; TK- , thymidine kinasenegative; WT, wild type.

Cumulative pathology scores were determined by tabulating the number of mice with a given pathology score and the average number of days that score was observed for each group, taking into consideration that each mouse had varying levels of pathology throughout the experiment. The average pathology score per mouse was then calculated for each group.

after challenge in all three groups of immunized mice. These results indicate that IVAG immunization with $\mathrm{TK}^{-} \mathrm{HSV}-2$ in WT and both groups of $\mathrm{LT} \alpha-1-$ mice provided sterile immunity against subsequent HSV-2 challenge.

\section{Immune cell populations in the vaginal mucosa of WT and $L T \alpha-/-$ mice after immunization and after challenge}

The complete protection against genital HSV-2 challenge in the absence of LNs in LT $\alpha-$ / - mice and LNs and spleen in LT $\alpha-$ / SPL groups led us to examine the immune cell populations in the vaginal mucosa of these mice before and after immunization, as well as after challenge by flow cytometric analysis. The vaginal mucosa of control, unimmunized LT $\alpha-/$ - mice contained a higher frequency of CD $3+\mathrm{CD} 4+\mathrm{T}$ cells $(2.79 \%)$ compared with WT mice ( $0.63 \%$; Figure 4a). Although the increase in $\mathrm{CD} 4+\mathrm{T}$ cells was $>20$-fold in WT mice compared with naive WT mice on day 14 after immunization, in the LT $\alpha-/$ - mice this increase was less remarkable (2.7-fold), suggesting delayed induction of T-cell responses (Figure 4a and Table 2). On day 22 after immunization and day 3 after challenge, the frequency of CD4 + T cells in the vaginal mucosa of all three groups of mice was comparable.

Similar to CD3 + CD $4+\mathrm{T}$ cells, higher frequency of $\mathrm{CD} 3+\mathrm{CD} 8+\mathrm{T}$ cells was observed in the vaginal mucosa of naive LT $\alpha-/$ - mice (1.10\% compared with $0.33 \%$, Table 2$)$. On day 22 , the highest percentage of $\mathrm{CD} 3+\mathrm{CD} 8+\mathrm{T}$ cells was noted in LT $\alpha-$ / - SPL mice (6.27\%; Table 2). After challenge, a 1.5-2-fold increase in the frequency of CD3 + CD8 + T cells was observed, particularly in LT $\alpha-$ / - SPL mice $(9.51 \pm 0.03 \%)$ compared with WT $(6.14 \pm 0.41 \%)$ and LT $\alpha-/-(6.45 \pm 1.69 \%)$ mice.

The B-cell population in the vagina was identified by coexpression of CD19 and major histocompatibility complex class II (MHCII). In naive LT $\alpha-/-$ mice, B cells were present at $\sim 10$ times higher frequency (4.34\%) compared with WT mice (0.063\%; Figure 4b and Table 2). On day 22 after immunization, the B-cell population in the vaginal tract was seen to increase 10-fold and 2-fold in WT and LT $\alpha-/-$ mice, respectively (Figure $4 \mathbf{b}$ ). After challenge, WT mice demonstrated a 3.5-fold increase in B-cell percentages compared with day 22 after immunization, whereas a small (LT $\alpha-/-, 2$-fold) or no (LT $\alpha-/-$ SPL) increase in B-cell frequency was seen in $\mathrm{LT} \alpha-/-$ mice.

In addition to $\mathrm{T}$ and $\mathrm{B}$ cells, the infiltration of professional antigen-presenting cells was also examined in all three groups of mice after immunization and challenge (Table 2). A small number of MHCII + CD11b + cells and MHCII + CD11c + cells were identified in the vaginal tracts of control mice and after immunization (Table 2). However, by day 22 after immunization and day 3 after challenge, highest frequency of antigen-presenting cells was seen in WT mice (Table 2).

Previous studies in our lab have found that protection against secondary HSV-2 challenge in WT mice correlated with the development of iVALTs, consisting of CD3 $+\mathrm{CD} 4+\mathrm{T}$ cells surrounded by MHC Class II + CD11c + antigen-presenting cells. ${ }^{5}$ We therefore examined whether protection against secondary HSV-2 challenge in LT $\alpha-$ / - mice correlated with iVALT formation (Supplementary Figure S2 online). Although LT $\alpha-$ / - 

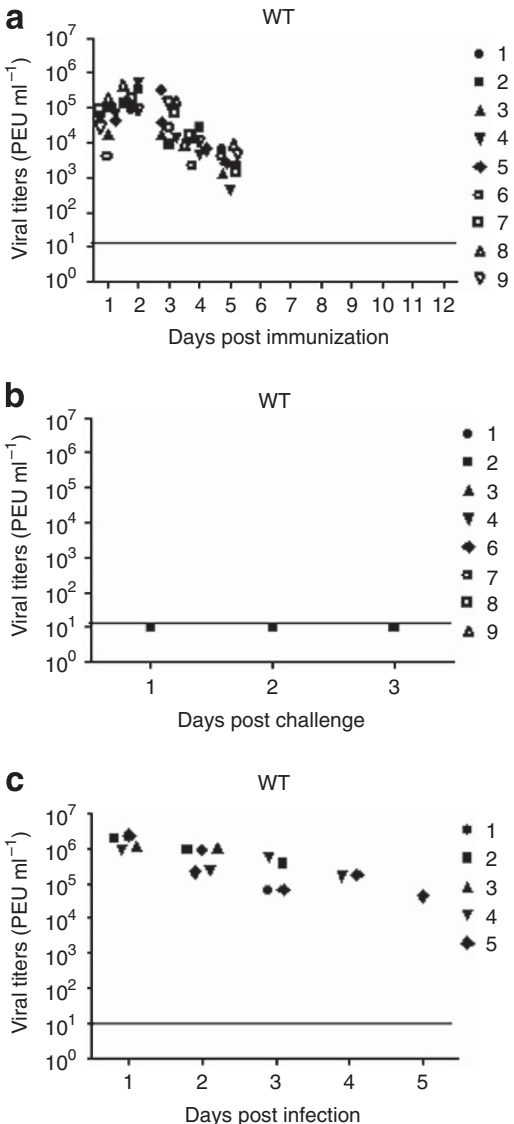
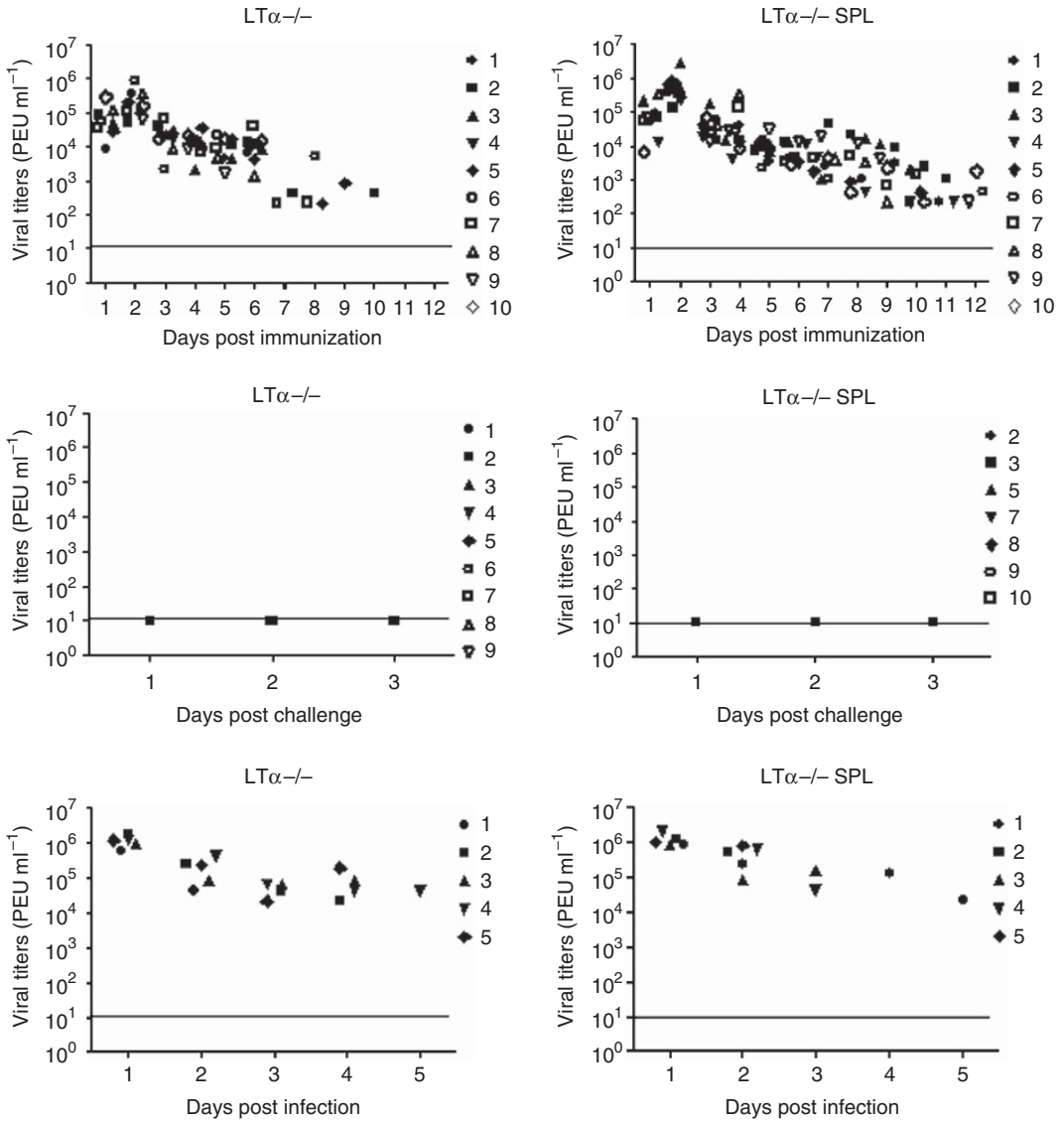

Figure 3 Viral titers of WT and LT $\alpha-/$ - mice following IVAG TK- HSV-2 immunization and HSV-2, strain 333, challenge. Vaginal washes were collected daily (a) after immunization and (b) after challenge, and (c) in nonimmunized control mice after infection, from all three groups and viral plaque assays were done. Plaques were counted and viral titers were expressed as PFU ml-1 . Each symbol represents a single animal. The dashed line shows the lower detection limit of the assay. Results are representative of four separate experiments with comparable results. HSV-2, Herpes simplex virus type 2; IVAG, intravaginal; LT $\alpha$, lymphotoxin- $\alpha$; SPL, splenectomized; $\mathrm{TK}^{-}$, thymidine kinase-negative; WT, wild type.

mice had a distinct increase in the number of CD4 + T cells present in the vaginal tract after challenge, they were nonpreferentially distributed throughout the tissue and did not form iVALT structures. WT mice had more MHCII + and CD11c + cells present, which were localized along with $\mathrm{CD} 4+\mathrm{T}$ cells, in lymphoid aggregates. Neither WT nor LT $\alpha-/-$ mice showed many CD8 + cells in the vaginal tracts after challenge.

Overall, these results indicate that in the naive LT $\alpha-/-$ mice there was an increased frequency of $\mathrm{B}$ and $\mathrm{T}$ cells compared with WT. Following IVAG immunization, although CD4 + T-cell numbers increased rapidly in the vaginal mucosa of WT mice, the increase in $\mathrm{CD} 4+\mathrm{T}$ cells was gradual in $\mathrm{LT} \alpha-/-$ mice, but by day 22 after immunization, all three groups had comparable number of CD $4+\mathrm{T}$ cells and this was maintained after challenge. Unlike CD4 + T cells, CD8 + T cells and B cells were detected at a higher frequency in vaginal mucosa of LT $\alpha-/-$ mice, compared with WT mice, both after immunization and after challenge. Furthermore, although iVALT formation was observed after challenge in WT mice as reported previously, no lymphoid aggregates were observed in LT $\alpha-$ / - after challenge.

\section{IgG and IgA levels in vaginal secretions and serum of immunized mice before and after HSV challenge}

The increase in the frequency of T- and B-cell populations after immunization and after challenge suggested that effector immune responses were present in the vaginal mucosa of LT $\alpha-/$ - and LT $\alpha-/$ - SPL mice, despite the absence of SLOs. Therefore, we first examined systemic and local antibody responses following $\mathrm{TK}^{-} \mathrm{HSV}-2$ immunization and HSV-2 challenge to determine B-cell responses. HSV-2-specific serum immunoglobulin $G(\operatorname{IgG})$ levels were increased significantly by almost 100-fold following HSV-2 challenge in WT mice compared with the levels observed after immunization (Figure 5a). However, the IgG response was not significantly increased in the serum samples of LT $\alpha-/-$ and LT $\alpha-/-$ SPL mice after challenge. In the vaginal washes, only the WT mice showed significant booster responses after challenge compared with postimmunization levels of HSV-2-specific IgG (Figure $5 \mathbf{b}$ ). Anti-HSV-2 immunoglobulin A (IgA) levels in the vaginal washes of WT mice were quite low but did show some booster response after challenge (Figure 5c). The HSV-2-specific IgA levels in LT $\alpha-/$ - and LT $\alpha-/$ - SPL mice were negligible 
a

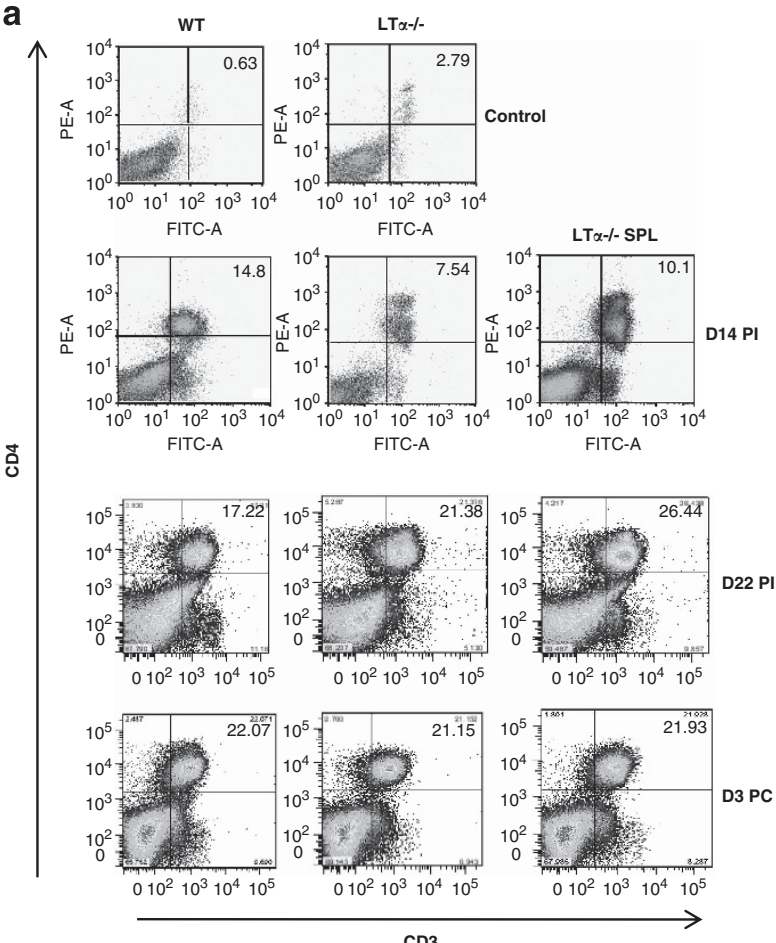

b

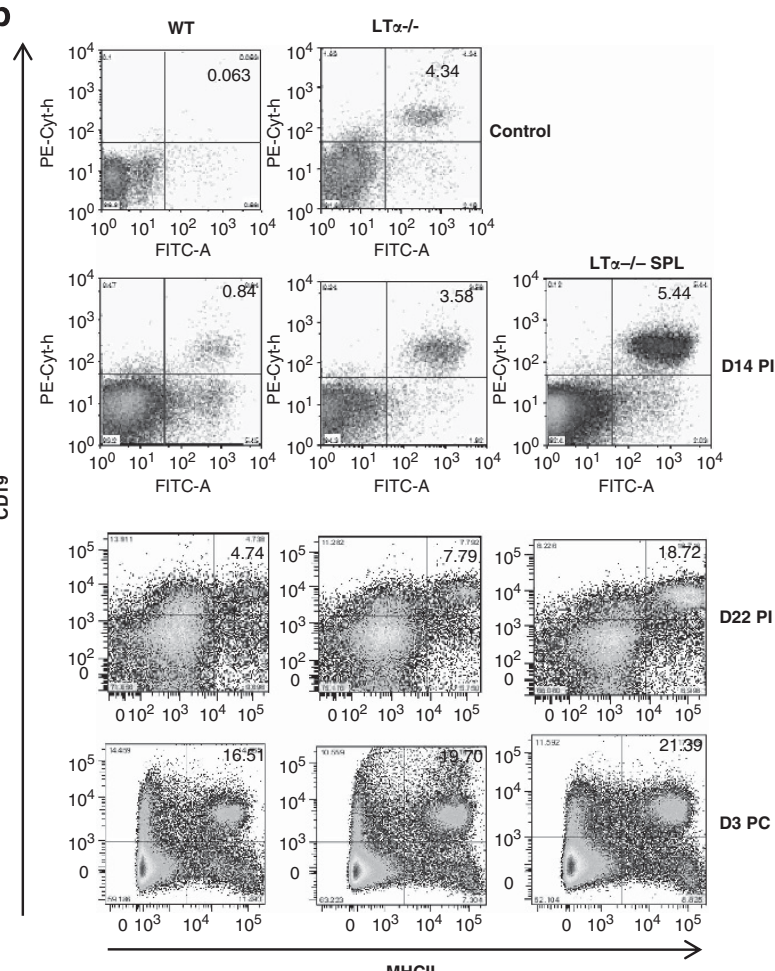

Figure 4 Flow cytometric analysis of immune cell populations in the vaginal mucosa of $L T \alpha-/-$ mice after immunization and after challenge. WT OVX, LT $\alpha-/-$ OVX, and LT $\alpha-/-$ OVX +SPL mice were immunized IVAG with $10^{5} \mathrm{PFU}$ of TK- HSV-2. At 6 weeks after immunization, mice were challenged IVAG with HSV-2, strain 333. Vaginal tracts were excised on days 14 and 22 after immunization and day 3 after challenge and single-cell preparations were made as described in the Methods. Vaginal cell preparations were stained with a panel of antibodies and analyzed for surface expression of markers for B cells, T cells, and APCs by flow cytometry. Viable cells were gated on lymphocytes. B cells were defined as the percentage of cells expressing MHCII and CD19. T-cell subsets were determined by expression of CD3, CD4, and CD8. Dendritic cells were defined as the percentage of cells expressing MHCII and CD11C and macrophages as percentage of cells expressing MHCIl and CD11b. Dot blots are shown for (a) T cells and (b) B cells. The WT control and day 3 postchallenge data are representative of two separate experiments, whereas $n=1$ for day 14 and 22 postimmunization data, as a result statistical analysis was not performed. The percentage of various cell populations, as well as the averages and s.d. for experiments with $n=3$, in control (unimmunized mice), days 14 and 22 (D14 and D22) after immunization, and day 3 (D3) after challenge is shown in Table 2. APC, antigen-presenting cell; HSV-2, Herpes simplex virus type 2; IVAG, intravaginal; LT $\alpha$, lymphotoxin- $\alpha$; MHCII, major histocompatibility complex class II; OVX, ovariectomized; PC, postchallenge; PI, postimmunization; SPL, splenectomized; TK-', thymidine kinase-negative; WT, wild type.

and no booster response was observed. These results indicate that although $\mathrm{LT} \alpha-/$ - mice did generate some IgG antibody responses, the overall HSV-2-specific IgG levels were significantly compromised compared with WT mice. Interestingly, the mucosal IgA responses were virtually absent in $\mathrm{LT} \alpha-/-$ mice.

To examine if the decreased levels of IgA in LT $\alpha-/-$ mice were in part due to defects in antibody production in these mice that has been previously reported, we examined the total IgG and IgA levels in serum and vaginal washes of nonimmunized control WT, LT $\alpha-/-$, and LT $\alpha-/$ - SPL mice (Supplementary Figure $\mathbf{S} 4$ online). With the exception of vaginal IgG levels, significantly decreased levels of $\operatorname{IgG}$ and IgA were present in the serum and vaginal washes of both groups of LT $\alpha-/-$ mice.

\section{Comparison of total and HSV-2-specific antibody responses in the vaginal secretions of $L T \alpha-/-$ mice after challenge}

As flow cytometric analysis results indicated increased proportions of B cells in the LT $\alpha-/$ - groups, but the HSV-2specific antibody titers were lower in vaginal tract of LT $\alpha-/$ groups compared with WT mice, we examined whether the impairment in antibody secretion was HSV-2 specific. Total and specific antibody responses in $\mathrm{LT} \alpha-/-$ mice were compared with WT mice. WT and LT $\alpha-/-$ mice had similar levels of total IgG, whereas LT $\alpha-$ / - SPL mice had marginally reduced levels (not significant, $P>0.05$ ) compared with WT mice (Figure 6a). However, both groups of LT $\alpha-/-$ mice had significantly reduced HSV-2-specific IgG responses in the vaginal tract after HSV-2 challenge compared with WT mice (Figure 6b). This suggests that in the absence of SLOs, the ability to mount specific antibody responses in the local mucosa following immunization was compromised.

\section{T-cell functional responses in the vaginal mucosa: HSV-2-} specific IFN $\gamma$-producing T cells, after immunization and after challenge

IVAG TK- HSV-2 immunization has been reported to induce protective immune responses that are primarily mediated by interferon- $\gamma($ IFN $\gamma)$-secreting CD $4+$ T cells. ${ }^{28-30}$ Therefore, we examined the presence of IFN $\gamma$-producing $\mathrm{CD} 3+\mathrm{T}$ cells in the vaginal mucosa of WT and LT $\alpha-/-$ mice. CD3 + CD $4+$ 
Table 2 Immune cell populations in the vaginal tract of WT OVX, LT $\alpha-/-$ OVX, and LT $\alpha-/-$ OVX + SPL mice

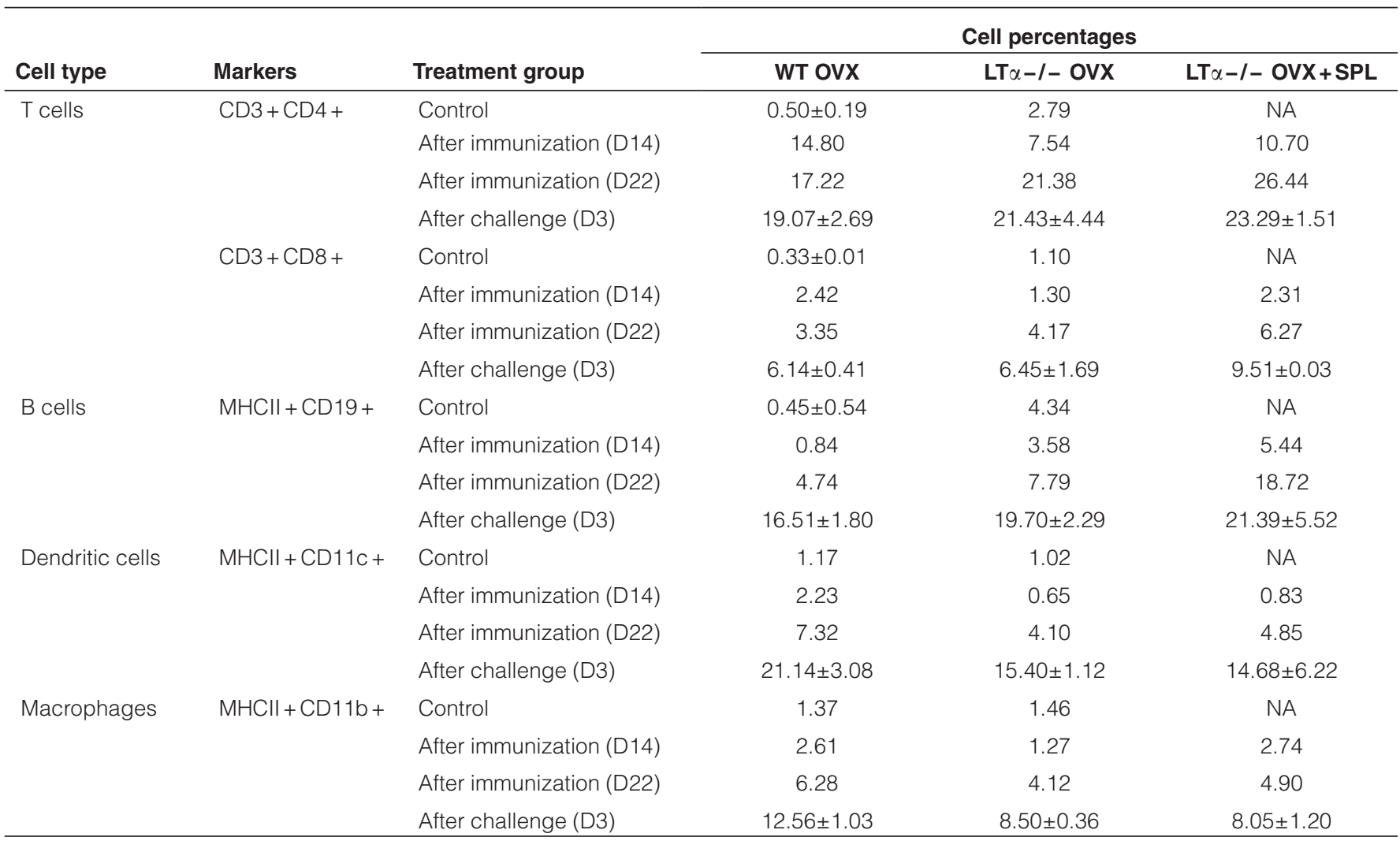

Abbreviations: LT $\alpha$, lymphotoxin- $\alpha$; MHCII, major histocompatibility complex class II; NA, not applicable; OVX, ovariectomized; SPL, splenectomized; WT, wild type. $\mathrm{N}=3$ for WT control and day 3 (D3) postchallenge experiments-cell percentages are expressed as average \pm s. $d$. As the results for the three independent experiments were very similar, we assessed different time points after immunization as single experiments.

and $\mathrm{CD} 3+\mathrm{CD} 8+\mathrm{T}$ cells were analyzed for the expression of intracellular IFN $\gamma$ directly following fresh isolation of these cells from the vaginal tract and following in vitro restimulation. $\mathrm{CD} 3+\mathrm{CD} 4+$ and $\mathrm{CD} 3+\mathrm{CD} 8+\mathrm{T}$ cells isolated 22 days after immunization from the vaginal mucosa of WT mice showed higher percentages of IFN $\gamma$ production compared with both groups of LT $\alpha-/$ - mice (Figure 7a,b, left). However, these differences in cell percentages did not translate into differences in cell numbers, as all three groups of mice had similar numbers of IFN $\gamma+$ T cells (both CD $4+$ and CD $8+$; Figure $\mathbf{7 b}$, right). Following in vitro restimulation, WT mice had higher percentages of IFN $\gamma+\mathrm{CD} 4+$ and CD $8+\mathrm{T}$ cells compared with LT $\alpha-/-$ mice (Figure 7c). Surprisingly, there was no increase in IFN $\gamma+$ T cells following in vitro restimulation compared with cells that were analyzed fresh out of the vaginal tract. In contrast to UV-HSV-2, stimulation with $\mathrm{CD} 3 / \mathrm{CD} 28$ dynabeads significantly increased the frequency of IFN $\gamma+\mathrm{T}$ cells (Figure 7d). Thus, the decreased numbers of IFN $\gamma+\mathrm{T}$ cells in LT $\alpha-/-$ mice were not due to poor T-cell viability.

At 3 days after challenge, flow analysis of freshly isolated vaginal tract immune cells showed that WT mice had higher percentages and total cell counts for both CD4 + IFN $\gamma+$ and CD8 + IFN $\gamma+$ cells compared with LT $\alpha-/$ - mice (Figure 8a,b). Following in vitro restimulation with UV-HSV-2, the percentage of cells (both $\mathrm{CD} 4+$ and $\mathrm{CD} 8+$ ) that were positive for intracellular IFN $\gamma$ increased by approximately twofold in all three groups of mice (Figure 8c,d, left). This percentage increased further when $\mathrm{T}$ cells were nonspecifically stimulated in the presence of CD3/CD28 dynabeads (Figure 8d, left). As expected, in vitro restimulation of vaginal cells with UV-HSV-2 resulted in higher percentages (1.7- to 2.5-fold) and total cell numbers (2- to 4 -fold) of IFN $\gamma+$ T cells in both WT and LT $\alpha-/-$ mice compared with LT $\alpha-/-$ SPL mice (Figure 8d). These results suggest that although $\mathrm{LT} \alpha-/-$ mice have similar percentages and total cell numbers of CD $3+\mathrm{CD} 4+$ and $\mathrm{CD} 3+\mathrm{CD} 8+$ cells (Figure 4 and Table 2), the number of HSV-2-specific IFN $\gamma$ producing $\mathrm{T}$ cells is decreased in LT $\alpha-/$ - compared with WT mice.

Further analysis showed that both after immunization (70-90\%) and after challenge (44-85\%), a majority of $\mathrm{IFN} \gamma+\mathrm{CD} 4+\mathrm{T}$ cells were CD $44+\mathrm{CD} 62 \mathrm{~L}-$ in concurrence with the previously described effector memory phenotype of T cells in this model (Supplementary Figure S3 online). ${ }^{31}$ Similar results were seen for IFN $\gamma+\mathrm{CD} 8+\mathrm{T}$ cells (not shown).

\section{DISCUSSION}

Previously, we have shown that WT OVX mice are completely protected against IVAG HSV-2 challenge following IVAG 

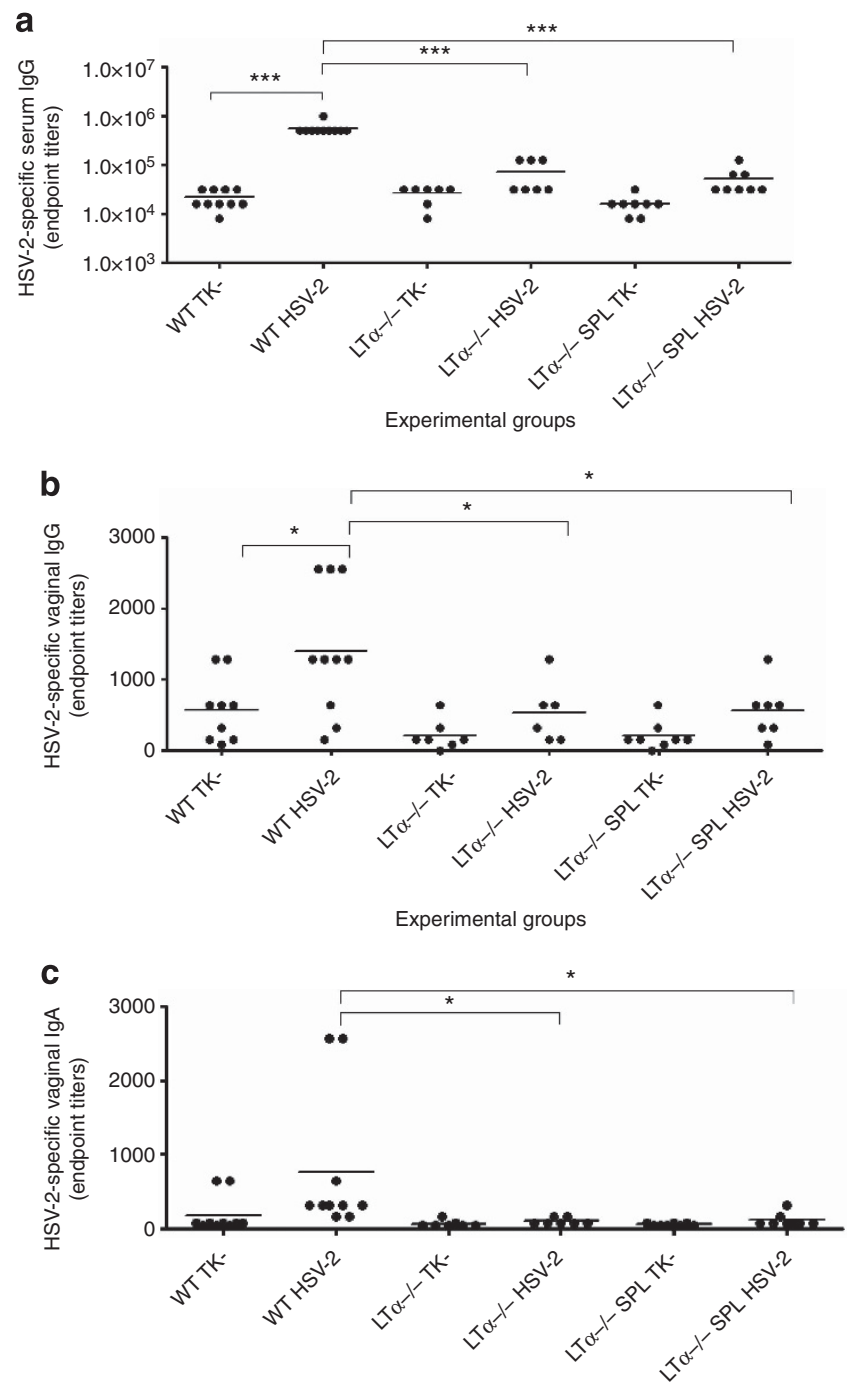

Experimental groups

Figure 5 HSV-2-specific antibody titers in vaginal washes and serum samples of WT OVX, LT $\alpha-/-$ OVX, and LT $\alpha-/-$ OVX + SPL mice both after immunization and after challenge. Vaginal washes were collected for 5 consecutive days after TK- HSV-2 immunization and pooled for each animal; serum samples were collected on day 24 after immunization. Vaginal washes were collected on days 1-5 after challenge and pooled for each animal; serum samples were collected on day 3 after challenge. HSV-2-specific IgG antibodies were measured in (a) serum and (b) vaginal washes and (c) $\operatorname{Ig} A$ antibodies were measured in vaginal washes by enzyme-linked immunosorbent assay (ELISA), and end point titers were determined. Each dot indicates an individual mouse. Bars show mean values for the group. Data are representative of two experiments with comparable results. $\mathrm{TK}^{-}$: after immunization; HSV2: after challenge. Statistical differences were determined by one-way analysis of variance followed by Tukey's post-test. ${ }^{*} P<0.05$; ${ }^{* * \star} P<0.001$ compared with after immunization. HSV-2, Herpes simplex virus type 2; Ig, immunoglobulin; LT $\alpha$, lymphotoxin- $\alpha$; OVX, ovariectomized; SPL, splenectomized; $\mathrm{TK}^{-}$, thymidine kinase-negative; WT, wild type.

immunization with an attenuated strain of HSV-2. ${ }^{5,32}$ In the present study, we determined whether memory effector responses against genital herpes infection were induced in the absence of SLOs and could effectively protect against a viral challenge in the genital mucosa. We used LT $\alpha-/-$ mice, which
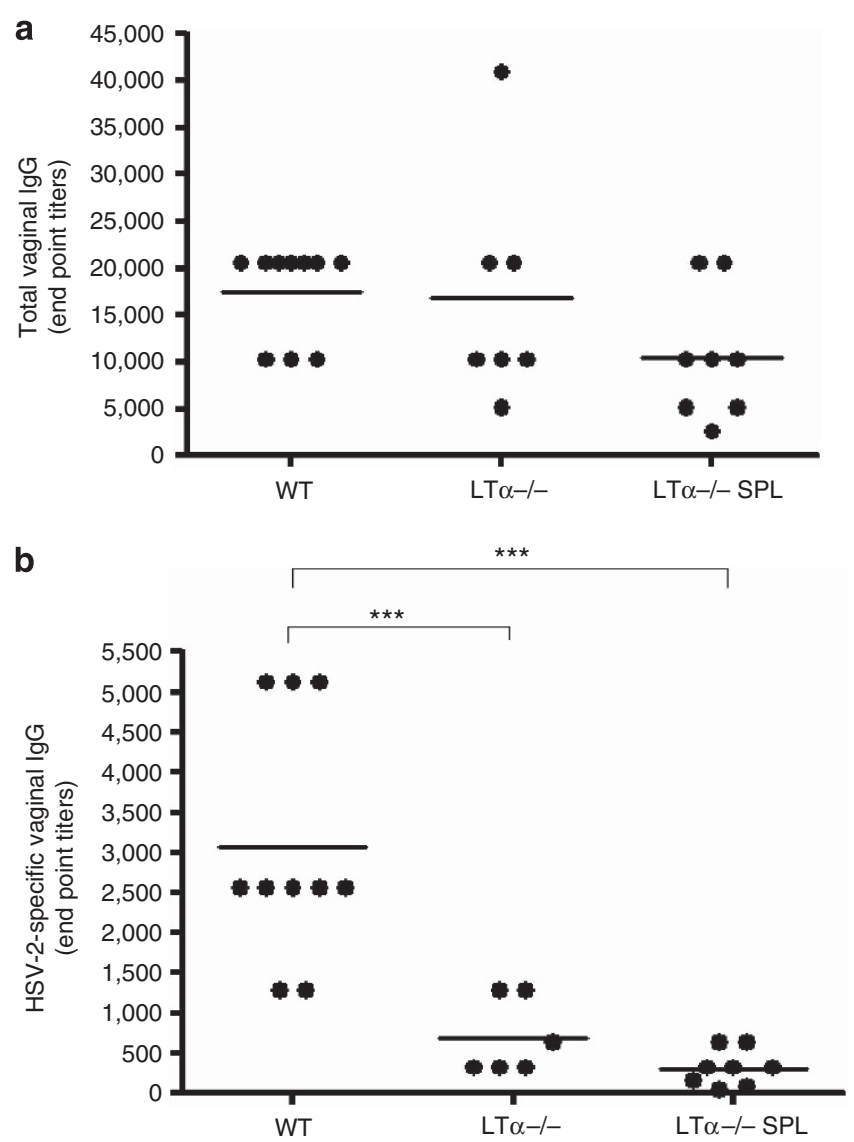

Figure 6 Total and HSV-2-specific IgG in vaginal washes at day 5 after challenge. WT OVX, LT $\alpha-/-$ OVX, and LT $\alpha-/-$ OVX +SPL mice were immunized IVAG with $10^{5} \mathrm{PFU}$ of TK- HSV-2. At 4 weeks after immunization, mice were challenged IVAG with HSV-2, strain 333. Vaginal washes were collected on days 1-5 after challenge in all three groups of mice. (a) Total IgG and (b) HSV-2-specific IgG antibodies in vaginal washes were measured by enzyme-linked immunosorbent assay (ELISA) and end point titers were determined. Each dot represents an individual animal. Bars show mean values for the group. Data are representative of two experiments with similar results. Statistical differences were determined by one-way analysis of variance followed by Tukey's post-test. ${ }^{\star \star \star} P<0.001$ compared with WT. HSV-2, Herpes simplex virus type 2; Ig, immunoglobulin; IVAG, intravaginal; LT $\alpha$, lymphotoxin- $\alpha$; OVX, ovariectomized; SPL, splenectomized; $\mathrm{TK}^{-}$, thymidine kinasenegative; WT, wild type.

lack all LNs, and surgically removed the spleens to ensure the absence of SLOs. We found that although the absence of SLOs delayed the induction and decreased the magnitude of immune responses following mucosal IVAG immunization, effector memory T-cell responses and IgG antibody responses were present in the vaginal mucosa of $\mathrm{LT} \alpha-/-$ mice that resulted in sterile protection following HSV-2 challenge in the genital tract. Although in our studies we used same parent strain of virus for immunization and challenge, others have shown that similar protection is seen against other strains of HSV-2. ${ }^{29,33}$

To examine the quality of immune protection generated in LT $\alpha-/$ - mice following mucosal IVAG immunization, gross genital pathology and viral shedding were examined. In the absence of SLOs, viral clearance from genital tract was delayed, 
a
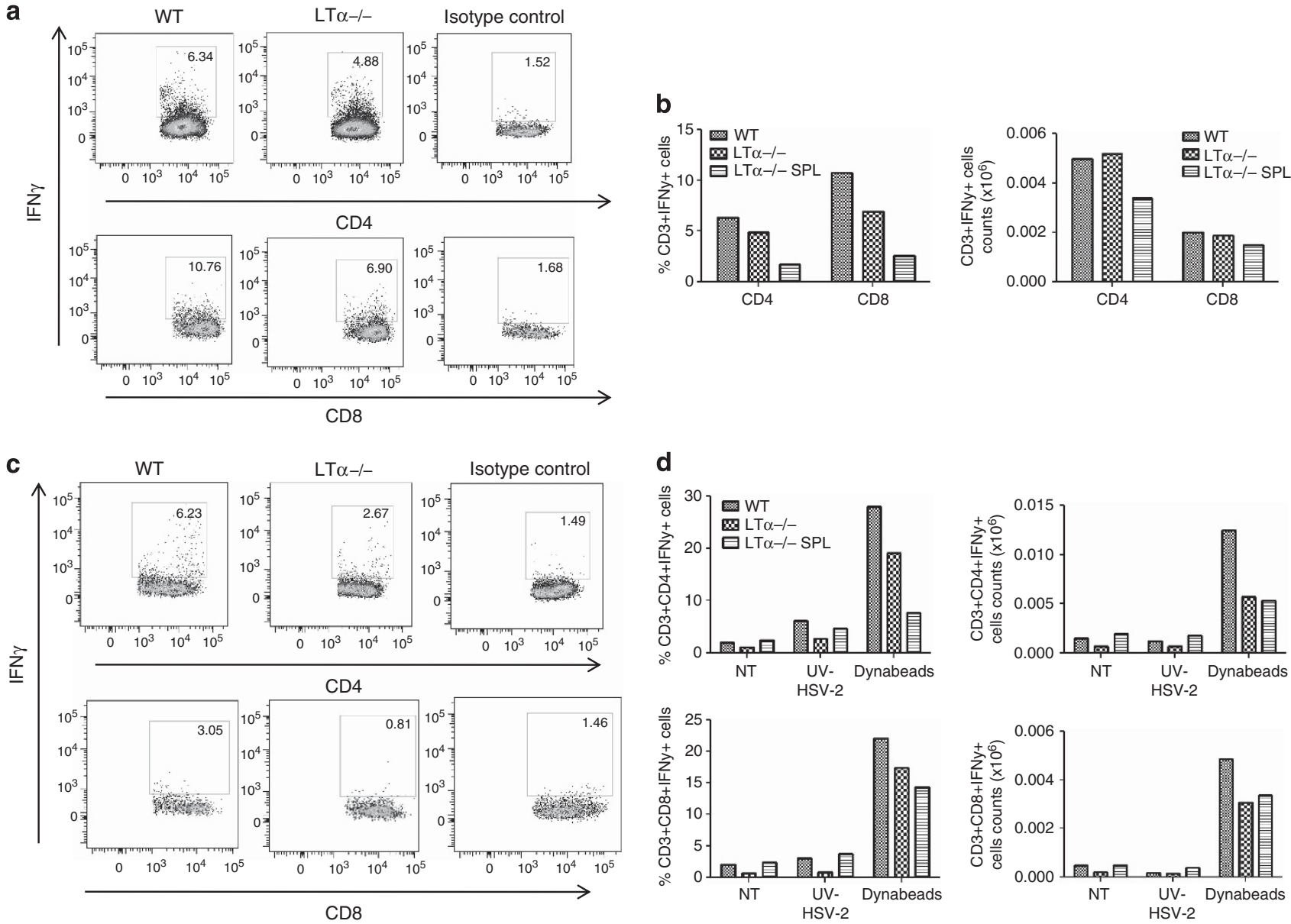

Figure 7 Flow cytometric analysis of IFN $\gamma+$ cells in vaginal tract day 22 after immunization. WT OVX, LT $\alpha-/-$ OVX, and LT $\alpha-/-$ OVX + SPL mice were immunized IVAG with $10^{5} \mathrm{PFU}$ of TK- HSV-2. Vaginal tracts were excised on day 22 after immunization and lymphocytes were isolated by enzymatic digestion. (a, b) Cells were stained for flow cytometric analysis the same day after isolation using the T-cell markers, CD3, CD4, CD8, and intracellular IFN $\gamma$. (c, d) Lymphocytes $\left(5 \times 10^{5}\right)$ were plated in 96-well plates and left NT or stimulated with UV-inactivated HSV-2 (UV-HSV-2; $10^{4}$ PFU) or $5 \mu \mathrm{l}$ of CD3/CD28 dynabeads $+\mathrm{IL}-2\left(50 \mathrm{U} \mathrm{ml}^{-1}\right)$ as a positive control. Cells were incubated at $37^{\circ} \mathrm{C}$ overnight and analyzed by flow cytometry the next day for the presence of IFN $\gamma+\mathrm{T}$ cells. Data are representative of two separate experiments with similar results. HSV-2, Herpes simplex virus type 2; IFN $\gamma$, interferon- $\gamma$; IL-2, interleukin-2; IVAG, intravaginal; LT $\alpha$, lymphotoxin- $\alpha$; NT, unstimulated; OVX, ovariectomized; SPL, splenectomized; TK- , thymidine kinase-negative; UV, ultraviolet; WT, wild type.

resulting in longer period of viral shedding and higher genital pathology, indicating that immune responses were generated more slowly in LT $\alpha-/$ - mice following immunization with $\mathrm{TK}^{-}$HSV-2. However, as all three groups of mice exhibited no vaginal pathology or viral shedding following HSV-2 challenge, this indicated that the immune responses generated were effective and sufficient to provide complete protection against a highdose viral challenge. To characterize the immune responses that were responsible for providing this sterile protection observed after challenge, HSV-2-specific IgG and IgA antibody levels were measured. In WT mice, serum and vaginal IgG levels were significantly increased after challenge, compared with after immunization. However, in both groups of LT $\alpha-/$ - mice, the booster response in serum and vaginal IgG was not significant and the overall levels of HSV-2-specific IgG after challenge were significantly lower as compared with WT mice. IgA responses were almost completely absent in LT $\alpha-/$ - mice. This supports previous studies that concluded that HSV-specific antibody responses are not the most critical component of the protective immune responses in this model and when present, levels of HSV-2-specific IgG rather than IgA levels, correlate with viral shedding and sterile immunity. 32,34

The findings of lower IgG antibody responses in LT $\alpha-/-$ mice compared with WT mice and the absence of IgA responses could be explained by the observations that isotype switching, and humoral immune responses in general, are impaired in LT $\alpha-/-$ mice. ${ }^{11,35}$ Studies have shown that the disruption of the splenic microarchitecture seen in LT $\alpha-/$ mice results in impaired IgG responses, rather than an intrinsic defect in LT $\alpha-/-$ B cells and T cells. ${ }^{35}$ This was further confirmed in our current studies where total IgA levels in serum and vaginal secretions of unimmunized LT $\alpha-/$ - mice were significantly decreased (Supplementary Figure S4 online).

It has been well established that IVAG immunization with $\mathrm{TK}^{-} \mathrm{HSV}-2$ induces protective immunity that is primarily mediated by IFN $\gamma$-secreting CD $4+$ T cells. ${ }^{28-29,36}$ The remarkable increase in the frequency of $\mathrm{CD} 4+\mathrm{T}$ cells following HSV-2 challenge in LT $\alpha-/$ - mice, which was comparable 

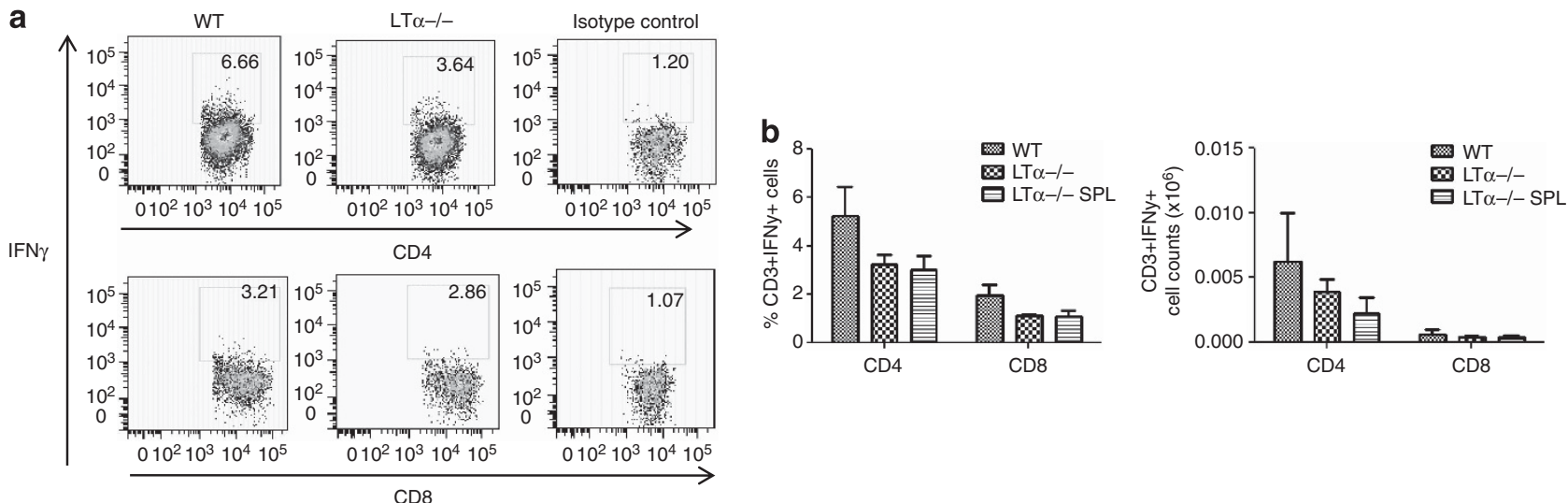

C
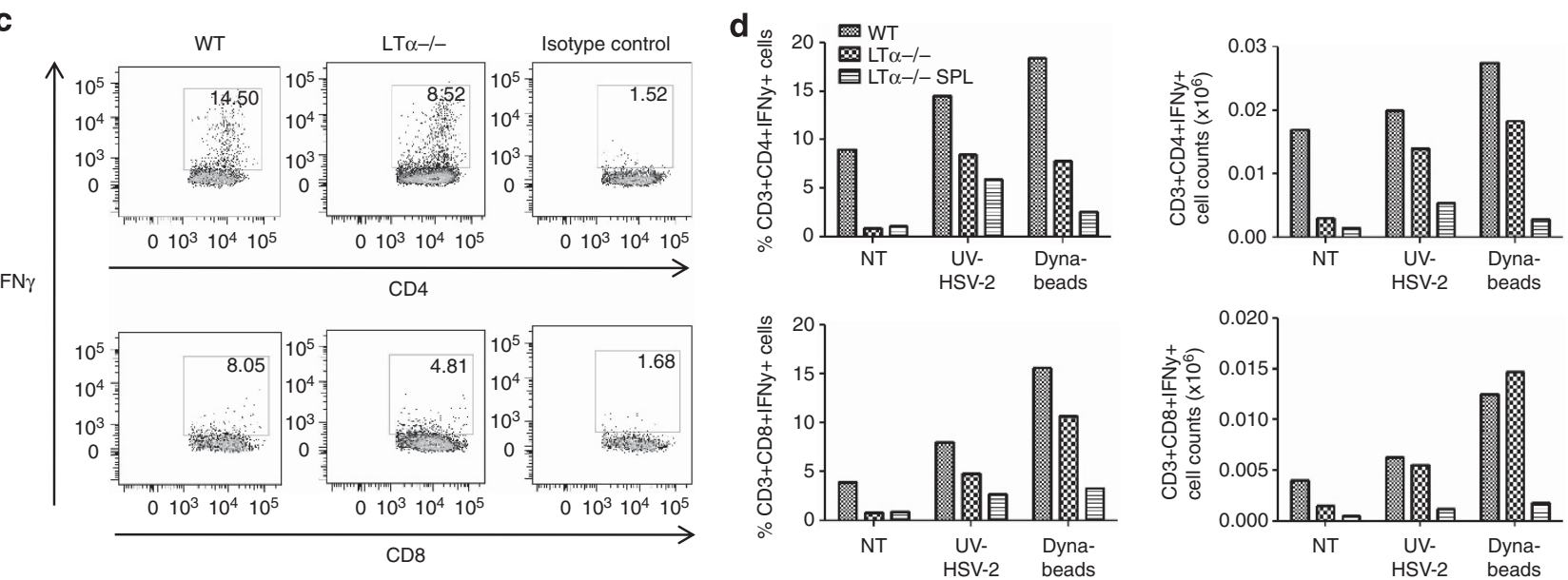

Figure 8 Flow cytometric analysis of IFN $\gamma+$ cells in vaginal tract day 3 after challenge. WT OVX, LT $\alpha-/-O V X$, and LT $\alpha-/-O V X+S P L$ mice were immunized IVAG with $10^{5} \mathrm{PFU}$ of TK- HSV-2. At 6 weeks after immunization, mice were challenged IVAG with $10^{5} \mathrm{PFU}$ of WT HSV-2, strain 333 . Vaginal tracts were excised on day 3 after challenge and lymphocytes were isolated by enzymatic digestion. (a, b) Lymphocytes were stained for flow cytometric analysis the same day after isolation using the T-cell markers: CD3, CD4, CD8, and intracellular IFN $\gamma$. (c, d) Lymphocytes were plated in 96-well plates and left NT or stimulated with UV-inactivated HSV-2 (10 $\left.{ }^{4} \mathrm{PFU}\right)$ or $5 \mu$ l of CD3/CD28 dynabeads (Invitrogen) + IL-2 (50U ml ${ }^{-1}$ ) as a positive control. Cells were incubated at $37^{\circ} \mathrm{C}$ overnight and analyzed by flow cytometry the next day for the presence of IFN $\gamma+\mathrm{T}$ cells. Data are representative of two separate experiments with similar results. HSV-2, Herpes simplex virus type 2; IFN $\gamma$, interferon- $\gamma$; IL-2, interleukin-2; IVAG, intravaginal; LT $\alpha$, lymphotoxin- $\alpha$; NT, unstimulated; OVX, ovariectomized; SPL, splenectomized; TK- ${ }^{-}$, thymidine kinase-negative; UV, ultraviolet; WT, wild type.

to the responses seen in WT mice, suggests that even in the absence of SLOs, mice were still able to mount a protective, effector memory T-cell response following IVAG immunization. To determine whether this T-cell response was specific for HSV-2, the number of HSV-2-specific, IFN $\gamma$-producing $\mathrm{CD} 3+\mathrm{T}$ cells were measured in the vaginal mucosa after immunization and after challenge. The results showed that $\mathrm{LT} \alpha-/$ - mice had a lower frequency of HSV-2-specific, IFN $\gamma$-producing CD $4+\mathrm{T}$ cells and $\mathrm{CD} 8+\mathrm{T}$ cells present in the vaginal mucosa compared with WT mice. Thus, the combined lack of TNFR/LT $\beta$ R signaling and SLOs appear to decrease the magnitude of HSV-2-specific IFN $\gamma+$ T-cell responses compared with that seen in WT mice. Overall, the delayed generation and decreased magnitude of immune responses following immunization did not affect the quality of protection in LT $\alpha-/$ - mice, as there was no viral shedding or pathology detected following challenge. One possible explanation for complete protection despite a decrease in overall immune responses could be that the extent of cellular and antibody responses generated in WT mice are quite robust and possibly exceed the magnitude of responses absolutely required for protection. Our results are in agreement with previous studies that have shown that although $\mathrm{LT} \alpha-/-$ mice have impaired cytotoxic and cytokine-mediated effector functions, they can still mount protective immune responses to a systemic infection of HSV. ${ }^{16,17}$

Previous studies have shown that the lung mucosa of LT $\alpha-/-$ mice makes effective primary and memory T- and B-cell responses to influenza. ${ }^{3,4}$ In addition, whereas Soderberg et al. ${ }^{18}$ found that protective T-cell responses to HSV-2 infection can be generated in the sacral LNs in LT $\beta$-deficient mice, the present study indicates that the genital mucosa itself, like the lungs, can mount protective antiviral memory responses in complete absence of SLOs. Interestingly, unlike the LT $\beta$-deficient mice where IgG and IgA antibody levels were maintained, in the present study, the absence of sacral LN in LT $\alpha-/-$ mice appeared to severely compromise HSV-2 specific antibody responses. ${ }^{18}$ Collectively, these studies point to the importance 
and autonomy of local mucosal responses in protecting against mucosal infections.

Although this study provides promising evidence regarding the independence of mucosal immune responses in the genital mucosa, the results raise important considerations that need to be addressed. Further studies are needed to determine whether, as has been previously shown in WT mice, in the absence of SLOs (i) immunization with subunit vaccines, with or without mucosal adjuvants, rather than with live attenuated virus, can replicate the protection seen in this study and (ii) immunization via nasal mucosa can provide protection in the genital mucosa. ${ }^{27,37-39}$ This information will allow a more realistic assessment of the implication of this study for mucosal vaccine strategies.

Overall, the results from this study provide further support for mucosal vaccines for sexually transmitted viral infections. Conventional vaccine strategies against HSV-2 and HIV-1 have been unsuccessful for over two decades, including the latest efficacy trial of HSV-2 gD-2 vaccine. ${ }^{24}$ As an important goal of vaccination against sexually transmitted infections is to induce and maintain immunity in the female genital tract, the finding that protective immune responses can be generated in the absence of SLOs indicates that immunization that generates effector memory responses at genital mucosa can provide adequate protection against subsequent viral exposures. The results also imply that once memory effector responses are generated, they can protect against genital tract infections independently and without involvement of other secondary lymphoid structures.

\section{METHODS}

Animals and surgeries. Female C57BL/6 and LT $\alpha-/-$ mice, 6-8 weeks old, were purchased from Jackson Laboratory (Bar Harbor, ME). All mice were housed and maintained under standard temperaturecontrolled conditions in special pathogen-free rooms that followed a 12-h day and 12-h night schedule. All animal protocols were approved by McMaster Animal Research Ethics Board. The ovaries were removed by making two bilateral incisions through the peritoneal wall, exteriorizing the fat, ligating the blood vessels, and removing the ovaries. The spleen was exteriorized through the incision on left side and removed by ligating the splenic vasculature. The incisions were closed by surgical clips and animals allowed to recover for 10 days.

HSV-2 inoculation and challenge. Groups of mice were immunized 10-14 days following OVX or OVX + SPL. Mice were anesthetized using injectable anesthetic ( $150 \mathrm{mg}$ of ketamine per $\mathrm{kg} / 10 \mathrm{mg}$ of xylazine per $\mathrm{ml}$ ) given intraperitoneally, placed on their backs, and immunized IVAG with $10^{5} \mathrm{PFU}(10 \mu \mathrm{l})$ of $\mathrm{TK}^{-} \mathrm{HSV}-2$, strain 333 . At $4-6$ weeks after immunization, mice were challenged IVAG with $10^{5} \mathrm{PFU}(10 \mu \mathrm{l})$ of wild-type HSV-2, strain 333.

Collection of vaginal washes and serum. Serum was collected on day 24 following IVAG immunization and day 3 following IVAG HSV-2 infection. Blood samples were obtained by retro-orbital bleeding, clotted at room temperature, and the serum was collected, re-centrifuged, and stored at $-70^{\circ} \mathrm{C}$. Vaginal washes were collected for 5 consecutive days following both IVAG immunization and challenge, by pipetting twice with $30 \mu$ of phosphate-buffered saline in and out of the vagina 6-8 times to give a total of $60 \mu$ l per mouse and stored at $-70^{\circ} \mathrm{C}$.
Genital pathology and viral titration. Genital pathology following $\mathrm{TK}^{-}$ HSV-2 immunization and HSV-2 strain 333 challenge was monitored daily and was scored on a five-point scale, as described before. ${ }^{6}$ Viral titers in vaginal washes were determined by plaque assay, as described before. ${ }^{6}$ Briefly, Vero cells were grown to confluence in 12-well plates: vaginal washes were diluted $\left(10^{-1}\right.$ to $\left.10^{-7}\right)$ and added to Vero cell monolayers. Infected monolayers were incubated at $37^{\circ} \mathrm{C}$ for $2 \mathrm{~h}$ and then overlaid with $\alpha$-modified Eagle's medium supplemented with $0.05 \%$ human immune serum globulin (Talecris Biotherapeutics Inc., Research Triangle Park, NC). At $48 \mathrm{~h}$ after infection, monolayers were fixed and stained with crystal violet, and viral plaques were counted. The number of $\mathrm{PFU} \mathrm{ml}{ }^{-1}$ was calculated by taking into account the dilution factors.

Real-time PCR for HSV-2 DNA. Viral DNA was isolated from vaginal wash samples using QIAamp MinElute Virus Spin Kit (QIAGEN Inc., Toronto, ON, Canada) according to the manufacturer's guidelines. Each viral DNA sample $(5 \mu \mathrm{l})$ was added to $12.5 \mu \mathrm{l} \mathrm{RT}^{2}$ Real-Time SYBR Green/ROX PCR Master Mix (SA Biosciences, Mississauga, ON, Canada), $0.6 \mu \mathrm{M}$ each forward and reverse primers (HSV DNA-pol; F: 5' -ATGGTGAACATCGACATGTACGG-3', R: 5' -CCTCCTTGTCGAGGCCCCGAAAC-3'; Integrated DNA Technologies, Coralville, IA), and $7.2 \mu$ l of water. Samples underwent 40 cycles of PCR, and the fluorescent dyes in each reaction were read automatically during PCR cycling in a 7900HT Fast Real-Time PCR System (Applied Biosystems, Carlsbad, CA). To quantify the amount of viral DNA in each sample, a standard curve was generated using known quantities of HSV-2 Quantitated Viral DNA (Advanced Biotechnologies, Columbia, MD).

Enzyme-linked immunosorbent assay for anti-HSV-2 gB IgG and IgA. HSV-2 gB-specific antibody titers were determined by enzyme-linked immunosorbent assay, as described before. ${ }^{27}$ Briefly, 96-well flat-bottom Maxisorp plates (Invitrogen, Burlington, ON, Canada) were coated with $2.5 \mu \mathrm{g} \mathrm{ml}^{-1}$ of recombinant gB protein (Chiron, Emeryville, CA) or purified antibodies (goat anti-mouse IgG or goat anti-mouse IgA, both purchased from Southern Biotech, Birmingham, AL) overnight at $4^{\circ} \mathrm{C}$. Twofold serial diluted samples were added and incubated overnight at $4^{\circ} \mathrm{C}$. Biotin-labeled goat anti-mouse IgG or goat anti-mouse IgA (Southern Biotech) was used at a concentration of $1 \mu \mathrm{g} \mathrm{ml}^{-1}$ and plates were developed with extravidin-peroxidase and tetramethyl benzidine (Sigma, St Louis, MO) and read at an optical density of $450 \mathrm{~nm}$. End point titers were determined and expressed as mean titers. The mean background optical density value of nonimmune mice was taken two times as the cutoff for determining positive values.

Vaginal cell preparation and culture. The vaginal tissue was minced and digested $2 \times$ in $15 \mathrm{ml}$ of RPMI containing $150 \mathrm{mg} \mathrm{ml}^{-1}$ collagenase A (Roche, Manheim, Germany) for $1 \mathrm{~h}$ each at $37^{\circ} \mathrm{C}$ and supernatants were collected. The remaining tissue and supernatants was passed through a $40 \mu \mathrm{m}$ filter (Small Parts, Miami Lakes, FL) to collect single cells. Cells were centrifuged for $10 \mathrm{~min}$ at 1,200 r.p.m. and resuspended in $0.2 \%$ bovine serum albumin for flow cytometric analysis or $10 \%$ fetal calf serum/ RPMI for cell culture. Cells were tested for HSV-2-specific IFN $\gamma$ production by in vitro stimulation with $10^{4} \mathrm{PFU}$ ultraviolet (UV)-inactivated HSV-2. As negative and positive controls, cells were either left unstimulated or stimulated with $2 \times 10^{5} \mathrm{CD} 3 / \mathrm{CD} 28$ dynabeads (Invitrogen) $+50 \mathrm{U} \mathrm{ml}^{-1}$ interleukin-2 (Peprotech, Rocky Hill, NJ), respectively. Cultures were incubated in the presence of GolgiPlug (BD Biosciences, Mississauga, Canada) for the last $4 \mathrm{~h}$ of $24 \mathrm{~h}$ culture.

Flow cytometry. Cell preparations were resuspended to a density of $10^{6}$ cells per $\mathrm{ml}$ and stained for cell surface markers using the following antibodies for $30 \mathrm{~min}$ at $4{ }^{\circ} \mathrm{C}$ : FITC anti-mouse MHCII, eFluor- 450 anti-mouse CD11b, PE anti-mouse CD11c, Pacific blue anti-mouse CD3, $\mathrm{PE}$ anti-mouse CD4, PE-Cy7 anti-mouse CD8 (eBioscience, San Diego, CA), and PE-Cy7 anti-mouse CD19 (BD Biosciences). For intracellular 
cytokine staining, cells were resuspended in Fixation/Permeabilization solution (BD Biosciences) and washed and resuspended in $1 \times$ BD Perm/ Wash buffer and stained with either FITC anti-mouse IFN $\gamma$ (Biolegend, San Diego, CA) or FITC IgG1 isotype control (eBioscience, San Diego, CA). Stained cells were analyzed by flow cytometric analysis using a BD LSRII Flow Cytometer and analyzed using FlowJo Software (TreeStar, Ashland, OR).

Statistical analysis. Statistical analysis was performed using Graph Pad Prism 3.02 (GraphPad Software, San Diego, CA). Viral shedding and antibody titers were analyzed by one-way analysis of variance followed by Tukey's post-test. Statistical significance was defined as $P<0.05$. For antibody titers, Grubbs' test was performed to remove any outliers.

SUPPLEMENTARY MATERIAL is linked to the online version of the paper at http://www.nature.com/mi

\section{ACKNOWLEDGMENTS}

This work was supported by research grants from Canadian Institutes of Health Research (CIHR), Ontario HIV Treatment Network (OHTN), and Canadian Foundation of AIDS Research (CANFAR) to C.K. C.K. is a recipient of an OHTN Scholarship Award and a New Investigator's Award from CIHR. K.L.R. is a recipient of an Ontario Graduate Scholarship.

\section{DISCLOSURE}

The authors declared no conflict of interest.

(c) 2013 Society for Mucosal Immunology

\section{REFERENCES}

1. Youngman, K.R., Lazarus, N.H. \& Butcher, E.C. Lymphocyte homing: chemokines and adhesion molecules in T cella dn IgA plasma cell localization in the mucosal immune system. In Mucosal Immunology Vol 1: (Mestecky, J.L.M., Strober, W., Bienenstock, J., McGhee, J.R. \& Mayer, L., eds) 667-680 Elsevier, Burlington, MA, 2005.

2. Brandtzaeg, P. Function of mucosa-associated lymphoid tissue in antibody formation. Immunol. Invest. 39, 303-355 (2010).

3. Moyron-Quiroz, J.E. et al. Persistence and responsiveness of immunologic memory in the absence of secondary lymphoid organs. Immunity 25, 643-654 (2006).

4. Moyron-Quiroz, J.E. et al. Role of inducible bronchus associated lymphoid tissue (iBALT) in respiratory immunity. Nat. Med. 10, 927-934 (2004).

5. Gillgrass, A.E., Tang, V.A., Towarnicki, K.M., Rosenthal, K.L. \& Kaushic, C. Protection against genital herpes infection in mice immunized under different hormonal conditions correlates with induction of vaginaassociated lymphoid tissue. J. Virol. 79, 3117-3126 (2005).

6. Gillgrass, A.E., Fernandez, S.A., Rosenthal, K.L. \& Kaushic, C. Estradiol regulates susceptibility following primary exposure to genital herpes simplex virus type 2, while progesterone induces inflammation. J. Virol. 79, 3107-3116 (2005).

7. Gommerman, J.L. \& Browning, J.L. Lymphotoxin/light, lymphoid microenvironments and autoimmune disease. Nat. Rev. Immunol. 3, 642-655 (2003).

8. Tumanov, A.V. et al. Dissecting the role of lymphotoxin in lymphoid organs by conditional targeting. Immunol. Rev. 195, 106-116 (2003).

9. Tumanov, A.V., Kuprash, D.V. \& Nedospasov, S.A. The role of lymphotoxin in development and maintenance of secondary lymphoid tissues. Cytokine Growth Factor Rev. 14, 275-288 (2003).

10. Alimzhanov, M.B. et al. Abnormal development of secondary lymphoid tissues in lymphotoxin beta-deficient mice. Proc. Natl. Acad. Sci. USA 94, 9302-9307 (1997).

11. Banks, T.A. et al. Lymphotoxin-alpha-deficient mice. Effects on secondary lymphoid organ development and humoral immune responsiveness. J. Immunol. 155, 1685-1693 (1995).

12. De Togni, P. et al. Abnormal development of peripheral lymphoid organs in mice deficient in lymphotoxin. Science 264, 703-707 (1994).

13. Koni, P.A. et al. Distinct roles in lymphoid organogenesis for lymphotoxins alpha and beta revealed in lymphotoxin beta-deficient mice. Immunity 6 , 491-500 (1997).

14. Berger, D.P. et al. Lymphotoxin-beta-deficient mice show defective antiviral immunity. Virology 260, 136-147 (1999).
15. Kumaraguru, U., Davis, I.A., Deshpande, S., Tevethia, S.S. \& Rouse, B.T. Lymphotoxin alpha $-/$ - mice develop functionally impaired CD8+ T cell responses and fail to contain virus infection of the central nervous system. J. Immunol. 166, 1066-1074 (2001).

16. Lee, B.J., Santee, S., Von Gesjen, S., Ware, C.F. \& Sarawar, S.R. Lymphotoxin-alpha-deficient mice can clear a productive infection with murine gammaherpesvirus 68 but fail to develop splenomegaly or lymphocytosis. J. Virol. 74, 2786-2792 (2000).

17. Lund, F.E. et al. Lymphotoxin-alpha-deficient mice make delayed, but effective, T and B cell responses to influenza. J. Immunol. 169, 5236-5243 (2002).

18. Soderberg, K.A., Linehan, M.M., Ruddle, N.H. \& Iwasaki, A. MAdCAM-1 expressing sacral lymph node in the lymphotoxin beta-deficient mouse provides a site for immune generation following vaginal herpes simplex virus-2 infection. J. Immunol. 173, 1908-1913 (2004).

19. Corey, L. \& Wald, A. Genital herpes. In Sexually Transmitted Diseases (Holmes, K.K., Sparling, P.F., Mardh, P.A., Lemon, S.M., Stamm, W.E., Piot, P., et al., eds) 285-312, McGraw-Hill, New York, 1999.

20. Looker, K.J., Garnett, G.P. \& Schmid, G.P. An estimate of global prevalence and incidence of herpes simplex virus type 2 infection. Bull. World Health Organ. 86, 737-816 (2008).

21. Cunningham, A.L. \& Mikloska, Z. The Holy Grail: immune control of human herpes simplex virus infection and disease. Herpes 8 (Suppl 1), 6A-10A (2001).

22. Koelle, D.M. \& Corey, L. Recent progress in herpes simplex virus immunobiology and vaccine research. Clin. Micro. Rev. 16, 96-113 (2003).

23. Stanberry, L.R. et al. Glycoprotein-D-adjuvant vaccine to prevent genital herpes. N. Engl. J. Med. 347, 1652-1661 (2002).

24. Belshe, R.B. et al. Efficacy results of a trial of a herpes simplex vaccine. N. Engl. J. Med. 366, 34-43 (2012).

25. Kaushic, C. The role of the local microenvironment in regulating susceptibility and immune responses to sexually transmitted viruses in the female genital tract. J. Reprod. Immunol. 83, 168-172 (2009).

26. Kaushic, C., Roth, K.L., Anipindi, V. \& Xiu, F. Increased prevalence of sexually transmitted viral infections in women: the role of female sex hormones in regulating susceptibility and immune responses. J. Reprod. Immunol. 88, 204-209 (2011).

27. Bhavanam, S., Snider, D.P. \& Kaushic, C. Intranasal and subcutaneous immunization under the effect of estradiol leads to better protection against genital HSV-2 challenge compared to progesterone. Vaccine $\mathbf{2 6}$, 6165-6172 (2008).

28. Harandi, A.M., Svennerholm, B., Holmgren, J. \& Eriksson, K. Protective vaccination against genital herpes simplex virus, type 2 infection in mice is associated with a rapid induction of local IFN-gamma-dependent RANTES production following a vaginal viral challenge. Am. J. Reprod. Immunol. 46, 420-424 (2001).

29. Harandi, A.M., Svennerholm, B., Holmgren, J. \& Eriksson, K. Differential roles of $\mathrm{B}$ cells and IFN-gamma-secreting CD4(+) T cells in innate and adaptive immune control of genital herpes simplex virus type 2 infection in mice. J. Gen. Virol. 82 (Pt 4), 845-853 (2001).

30. Milligan, G.N., Bernstein, D.I. \& Bourne, N. T lymphocytes are required for protection of the vaginal mucosa and sensory ganglia of immune mice against reinfection with herpes simplex virus type 2. J. Immunol. 160, 6093-6100 (1998).

31. Tang, V.A. \& Rosenthal, K.L. Intravaginal infection with herpes simplex virus type-2 (HSV-2) generates a functional effector memory T cell population that persists in the murine genital tract. J. Reprod. Immunol. 87, 39-44 (2010).

32. Gillgrass, A., Chege, D., Bhavanam, S. \& Kaushic, C. Estradiol limits viral replication following intravaginal immunization leading to diminished mucosal lgG response and non-sterile protection against genital herpes challenge. Am. J. Reprod. Immunol. 63, 299-309 (2010).

33. Johnson, A.J., Nelson, M.H., Bird, M.D., Chu, C.F. \& Milligan, G.N. Herpes simplex virus (HSV)-specific T cells activated in the absence of IFN-gamma express alternative effector functions but are not protective against genital HSV-2 infection. J. Reprod. Immunol. 84, 8-15 (2010).

34. Parr, E.L. \& Parr, M.B. Immunoglobulin G is the main protective antibody in mouse vaginal secretions after vaginal immunization with attenuated herpes simplex virus type 2. J. Virol. 71, 8109-8115 (1997).

35. Fu, Y.X. et al. Lymphotoxin-alpha (LTalpha) supports development of splenic follicular structure that is required for lgG responses. J. Exp. Med. 185, 2111-2120 (1997). 


\section{ARTICLES}

36. Parr, M.B. \& Parr, E.L. Vaginal immunity in the HSV-2 mouse model. Int. Rev. Immunol. 22, 43-63 (2003).

37. Tengvall, S, Josefsson, A., Holmgren, J. \& Harandi, A.M. CpG oligodeoxynucleotide augments HSV-2 glycoprotein D DNA vaccine efficacy to generate Thelper 1 response and subsequent protection against primary genital herpes infection in mice. J. Reprod. Immunol. 68, 53-69 (2005).
38. Olson, K. et al. Liposomal gD ectodomain (gD1-306) vaccine protects against HSV2 genital or rectal infection of female and male mice. Vaccine 28, 548-560 (2009).

39. Gallichan, W.S., Gurasachi, T. \& Rosenthal, K.L. Intranasal immunization with $\mathrm{CpG}$ oligonucleotides as an adjuvant dramatically increases $\operatorname{lgA}$ and protection against HSV-2 in the genital tract. J. Immunol. 166, 3451-3457 (2001). 